\title{
Risk of postnatal depression or suicide after in vitro fertilisation treatment: a nationwide case- control study
}

Josefin Vikström Eckevall, Gunilla Sydsjö, Mats Hammar, Marie Bladh and Ann Josefsson

\section{Journal Article}

\section{Tweet}

N.B.: When citing this work, cite the original article.

Original Publication:

Josefin Vikström Eckevall, Gunilla Sydsjö, Mats Hammar, Marie Bladh and Ann Josefsson, Risk of postnatal depression or suicide after in vitro fertilisation treatment: a nationwide casecontrol study, British Journal of Obstetrics and Gynecology, 2016

http://dx.doi.org/10.1111/1471-0528.13788

Copyright: Wiley: 12 months

http://eu.wiley.com/WileyCDA/

Postprint available at: Linköping University Electronic Press

http://urn.kb.se/resolve?urn=urn:nbn:se:liu:diva-132763

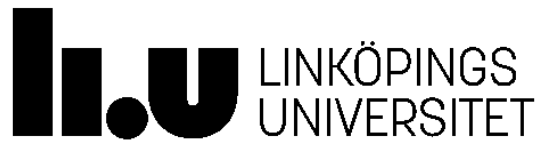




\section{Risk of postnatal depression or suicide after in vitro fertilization treatment: A nationwide case-control study}

Josefin Vikström MD, Gunilla Sydsjö PhD, Mats Hammar MD PhD, Marie Bladh MA, Ann Josefsson MD PhD

Affiliations for all authors:

Obstetrics and Gynecology, Department of Clinical and Experimental Medicine, Faculty of Health Sciences, Linköping University, Sweden

Department of Obstetrics and Gynecology in Linköping, County Council of Östergötland, Linköping, Sweden.

\section{Corresponding Author}

Josefin Vikström

Obstetrics and Gynecology, Department of Clinical and Experimental Medicine, Faculty of Health Sciences, Linköping University, Sweden

Department of Obstetrics and Gynecology in Linköping, County Council of Östergötland, Linköping, Sweden.

E-mail: Josefin.Vikstrom@liu.se, Telephone: +46703320527

Running title: Risk of postnatal depression after IVF treatment 


\begin{abstract}
Objective: To examine if women who undergo in vitro fertilization (IVF) treatment are at greater risk of postnatal suicide or postnatal depression (PND) requiring psychiatric care compared to women who conceive spontaneously.
\end{abstract}

Design: Case-control study using data from national registers.

Setting: Sweden during the period 2003-2009.

Population: Cases were 3532 primiparous women who had given birth following IVF treatment. An aged-matched control group of 8553 mothers was randomly selected from the medical birth register.

Methods: Logistic regression analyses were performed with PND as outcome and known risk factors of PND as well as IVF/spontaneous birth as covariates.

Main outcome measures: PND defined as ICD-10 diagnoses F32-39 within 12 months after childbirth.

Results: Initial analyses showed that PND was more common in the control group than the IVF group (0.8\% vs. 0.4\%; p=0.04). However, these differences disappeared when confounding factors were controlled for. A history of any psychiatric illness ( $p=.000$; $\mathrm{OR}=25.5$; $95 \% \mathrm{CI}=11.7-55.5)$, any previous affective disorder $(\mathrm{p}=, 000 ; \mathrm{OR}=26.0$; 95\%CI=10.5-64.0) or specifically a personality disorder ( $\mathrm{p}=.028$; OR=3.8; $95 \% \mathrm{CI}=1.2-$ 12.7) increased the risk of PND. No woman in either group committed suicide during the first year after childbirth.

Conclusions: While mothers who receive IVF treatment are not at increased risk of PND, the risk is increased among mothers with a history of mental illness.

Keywords: IVF, infertility treatment, postnatal depression, postnatal mental illness 
Tweetable abstract: A Swedish study on 3532 women showed that IVF treatment does not increase the risk of postnatal depression. 


\section{Introduction}

It is generally reported that about $13 \%$ of women in developed countries suffer from postnatal depression (PND) ${ }^{1,2}$. However, studies have shown that the prevalence of PND cases that require psychiatric care is $0.3 \%{ }^{3}$ and that the prevalence of hospitalizations due to PND is $0.06 \%-0.26 \%{ }^{4}$. Apart from the negative effects on the woman's health, PND can also have a negative impact on mother-child interaction and child development ${ }^{5-7}$.

Risk factors of PND include previous psychiatric illness ${ }^{8-10}$, specifically depression ${ }^{9-10}$, antenatal depression and anxiety ${ }^{8-10}$, stressful life events ${ }^{8-10}$, lack of social support ${ }^{8-10}$, a negative attitude towards pregnancy ${ }^{8-9}$, neuroticism ${ }^{9}$, low self-esteem , poor marital relationship, low socioeconomic status, being single, obstetrical stressors, and a difficult temperament in the infant ${ }^{9}$.

However, the above mentioned risk factors cannot fully explain the variance in PND incidence ${ }^{11}$. Gleicher (2007) argued that the pathogenesis of PND could be autoimmune based on similarities between PND and well-known autoimmune disorders ${ }^{12}$. The rationale behind this was that pregnancy reveals underlying dispositions and cause recurrences for both autoimmune and affective disorders, both exacerbate during late pregnancy or the postpartum period and both have shared risk factors such as primiparity and childbirth by caesarian section ${ }^{12}$.

It has also been hypothesized that hormone exposure, specifically disruptions in the hypothalamus-pituitary-adrenal (HPA) axis, during pregnancy might be a factor in the PND pathogenesis ${ }^{11}$. The theory behind this is that stress, which is a well-known cause of depression, is closely linked to the function of the HPA-axis and evidence of HPA-axis 
dysregulation during the postpartum period has been found ${ }^{11}$. Since infertility and its treatment causes levels of stress to rise during and after treatment ${ }^{12,13}$ one might hypothesize that the risk of HPA-axis dysregulation, and thus PND, would be increased in these women. Notably, An et al (2013) found a positive association between cortisol levels and state anxiety in women treated with in vitro fertilization (IVF) ${ }^{14}$.

However, most studies, with a few exceptions ${ }^{16-18}$, have found the risk of developing postnatal depressive symptoms or PND to be equal when those who have conceived using assisted reproductive technologies (ART) are compared to those who have conceived spontaneously ${ }^{19-23}$. However, Ross et al (2011) reported that most studies have failed to control for known risk factors of PND ${ }^{20}$. In general, women who undergo infertility treatment have fewer risk factors of PND. They have a higher socioeconomic status, enjoy relationships of a better quality with a longer duration and are more psychologically welladjusted than those who conceive naturally ${ }^{24-28}$. Therefore, Ross et al. (2011) speculated that future studies controlling for these factors may in fact find the risk of PND to be increased among women who have undergone infertility treatment. Also, most previous studies have used self-report depression screening instruments rather than diagnostic criteria to identify cases $^{20}$. Since an increasing number of couples use IVF treatment to conceive ${ }^{29}$ it is important to determine if this treatment increases the risk of PND, which might have grave consequences on the health of both mother and child ${ }^{5-7}$.

We hypothesized that women who receive IVF treatment are at increased risk of PND since previous studies have found the risk among these women to be equal to those who have conceived spontaneously while failing to control for possible confounding factors. The aim of the present study was to examine if women who undergo IVF treatment are at greater risk of 
postnatal suicide or PND requiring psychiatric care compared to those who conceive spontaneously.

\section{Methods}

Population

All primiparous women born from January $1^{\text {st }} 1973$ to December $31^{\text {st }} 1983$ who were included in the Swedish IVF register from January $1^{\text {st }} 2003$ to December $31^{\text {st }} 2009$ were included in the study ( $\mathrm{n}=3532)$. This time interval was chosen so that as much information as possible would be available from all registers for all participants. A control group of women ( $\mathrm{n}=8553$ ) who had conceived spontaneously and subsequently given birth were, using SPSS sample procedure, randomly selected from the Medical Birth Register (MBR). In order to increase the power of the study, the control group chosen was more than twice the size of the IVF group. The groups were matched for age.

\section{Registers}

The Medical Birth Register (MBR)

The MBR includes nearly all pregnancies that have resulted in births in Sweden since 1973 and contains information about the pregnancy, delivery and antenatal health of the child. Due to reporting errors, one to three percent of deliveries are missing from the register each year. The register is based on the medical charts from antenatal, obstetric as well as neonatal care $^{30}$ and has been thoroughly described by Harlow et al. (2007) ${ }^{31}$.

Using the personal identification number (PIN) of the women, information about the height, weight, parity, previous miscarriages, previous experience of delivering a stillborn child or death of a child during the first month, gestational week at childbirth as well as mode of childbirth was collected. Birth weight was categorized into extremely low birth weight 
(<1000g, ELBW), very low birth weight (1000g-1499g, VLBW), low birth weight (15002499g, LBW) and normal birth weight (>2500g). Gestational age was divided into <28 weeks (extremely preterm), 28-31 weeks (very preterm), 32-36 weeks (preterm), 37-40 weeks (term) and $>40$ weeks (post term).

\section{The National Patient Register (NPR)}

The NPR contains information about all patients who have been discharged from hospital or treated in outpatient care. It does not contain diagnoses received in general practice. This register has been thoroughly described by Harlow et al (2007) ${ }^{31}$. Pre- and postnatal psychiatric diagnoses were collected from the NPR. The diagnoses were limited to the past five years before, and one year after, childbirth and were chosen from the fifth chapter of the ICD-10, containing the mental and behavioural disorders. The DSM-IV definition of postnatal depression is limited to the first four weeks after childbirth. However, mental

illnesses occurring as late as 12 months after childbirth are often defined as postnatal ${ }^{1932}$. In order to include all possible postnatal depression cases, a one-year time interval was used in this study. The diagnoses retrieved from the register for the five years prior to childbirth were F20-29 (Schizophrenia, Schizotypal and Delusional disorders), F30-39 (Affective disorders), F40 (Phobic disorders), F41 (Other anxiety disorders), F42 (obsessive-compulsive disorder), F43 (Reactions to severe stress) and F60 (Disorders of adult personality and behavior) since a history of psychiatric illness is the greatest risk factor of postnatal depression ${ }^{9,33-34}$. The diagnoses included in the postnatal depression definition were F32-39. No diagnoses of psychotic disorders were included. Prevalence of suicides was also collected from this register. 
The registration of IVF pregnancies in Sweden is thoroughly described by Källén et al $(2005)^{35}$ and the Swedish National Board of Health and Welfare (2009) ${ }^{36}$. This register was started in 1982 and is held by the National Board of Health and Welfare. All women who have been treated with IVF and subsequently given birth to a child are included. A file based on the woman's PIN is set up which includes information on the laboratory conducting the treatment, the date, type of treatment etc. ${ }^{35-36}$. From this register the PIN numbers of the women who had undergone IVF treatment were collected.

The Total Population Register (TPR), the Education Register (ER) and the Population and Housing Census (PHC)

These registers are held by Statistics Sweden. The TPR was established in 1968 and includes information on births, deaths, migrations and marital status ${ }^{37}$. Information about marital status was gathered from this register and divided into 1, Married/Cohabiting and 2, Single/Divorced/Widowed. The ER contains information about the educational level of the population which is collected continuously ${ }^{38-39}$. From this register, information about highest level of education was collected and divided into 1, Secondary School, 2, High School and 3, University.

\section{Statistics}

The calculations were performed using IBM SPSS 20.0 (IBM Inc., Armonk, USA). Chi square tests were performed to determine differences between the two groups in demographics (highest level of education, marital status), experiences from previous pregnancies (miscarriages, previous experience of stillborn child or death of child during the first month), factors of the current pregnancy (plurality, mode of delivery), psychiatric diagnoses over the last five years and postnatal depression. 
A binary logistic regression analysis with postnatal depression (F32-39) as the dependent variable was performed. The covariates chosen were known risk factors of postnatal depression. In order to fulfil the main aim of the study, group (1 IVF, 2 Controls) was added a covariate. The variable previous miscarriages was also included since there was a significant difference between the two groups in the chi-square analyses for this variable. When all the covariates were added to the same model the regression was saturated. The covariates were therefore added to the regression in the above mentioned groups (demographics, previous pregnancies, current pregnancy, factors in delivery, maternal somatic illness, history of psychiatric illness), one group at a time to find those who were the most associated with the outcome. Those who were significant were added in a multiple regression model so that those covariates that were the most associated with the outcome would be analyzed together. Due to a high correlation between the variables any psychiatric disorder and any affective disorder separate models were performed for these two variables. In each model, all other potential confounders that were significantly associated with the outcome in the binary logistic regression analyses were included.

\section{Results}

\section{Demographics}

In total, 3532 primiparous women who had given birth as a result of IVF treatment were included in the study. An age-matched, primiparous control group $(n=8553)$ of women was chosen from the MBR. The mean age at the time of giving birth was 29.2 years. Four percent $(n=120)$ of the women in the IVF group were single compared to $12.4 \%(n=367)$ of those in the control group ( $\mathrm{p}=.000$ ). The controls were more likely to have completed high school as their highest level of education while the women in the IVF group were more likely to either 
have left school after nine years or to have completed an education at university $(\mathrm{p}=.007)$ (Table 1).

Characteristics of previous pregnancies

Looking at all women, $0.1 \%(n=17)$ had previously experienced the death of a child either during labour or up until the first month after birth (Table 1). There were no significant differences between the two groups for this variable. The women in the IVF group (15.4\%, $n=543)$ were significantly more likely than those in the control group $(12.7 \%, n=1089)$ to have had one or more miscarriages $(\mathrm{p}=.000)$ (Table 1$)$.

Characteristics of the current pregnancy

The women in the IVF group were significantly more likely to give birth prematurely $(p=.000)$ and to give birth to a baby that weighed less than $2500 \mathrm{~g}$ compared to the women in the control group ( $p=.000)$ (Table 1$)$. Women in the control group were more likely than the IVF group to have an instrumental delivery $(p=.000)$ while the differences for acute and elective caesarean section were small and insignificant. The percentage of women who gave birth to two or more children was $1.6 \%$ in both groups.

History of psychiatric illness

In the last five years prior to giving birth, $2.5 \%(n=87)$ of the women in the IVF group and $4.2 \%(n=355)$ of those in the control group $(\mathrm{p}=.000)$ had been diagnosed with a psychiatric disease (Table 2). Fourteen (0.2\%) of the women in the control group and none of those in the IVF group had a history of mania or bipolar disorder while 39 (1.1\%) of those in the IVF group and 159 (1.9\%) of the controls were previously diagnosed with depression ( $p=.003)$. In regards to anxiety, 62 (1.8\%) of those in the IVF group and 240 (2.8\%) of the controls had 
previously received such a diagnosis $(\mathrm{p}=.001)$. Only one of the women who had received IVF and 6 of the controls had a history of psychosis or schizophrenia $(p=.681)$ while $7(0.2 \%)$ of those in the IVF group and $44(0.5 \%)$ of those in the control group had previously received a personality disorder diagnosis $(\mathrm{p}=.016)$ (Table 2).

Postnatal psychiatric diagnoses

Women in the control group ( $\mathrm{n}=66 ; 0.8 \%)$ were more likely than the women in the IVF group $(\mathrm{n}=15,0.4 \%)$ to receive a postnatal depression diagnosis $(\mathrm{p}=.04)$. When the women without a history of psychiatric illness were selected, the differences were not significant. None of the women in either group committed suicide during the first year after childbirth.

The binary logistic regression analysis with postnatal depression as the dependent variable showed that those who were single $(\mathrm{p}=.006$; $\mathrm{OR}=3.3$; $95 \% \mathrm{CI}=1.4-7.8)$, had a history of any psychiatric illness $(p=.000 ; O R=8.4 ; 95 \% C I=3.1-22.5)$ or specifically an affective $(p=.000$; $\mathrm{OR}=5.4 ; 95 \% \mathrm{CI}=2.4-12.5$ ) or personality disorder $(\mathrm{p}=.008$; $\mathrm{OR}=3.0 ; \mathrm{CI}=1.3-6.6)$ were at greater risk of a postnatal depression (Table 3). Those in the control group were more likely to be diagnosed with postnatal depression compared to those in the IVF group $(p=.037$; $\mathrm{OR}=1.8 ; 95 \% \mathrm{CI}=1.0-3.2)$. When the covariates with a significant relation to the outcome were added to the first multiple regression model the significant results remained for any previous psychiatric illness ( $\mathrm{p}=.000$; OR=25.5; $95 \% \mathrm{CI}=11.7-55.5)$ or specifically a personality disorder $(\mathrm{p}=.028$; OR=3.8; $95 \% \mathrm{CI}=1.2-12.7)$. In the second model the significant results remained for any previous affective disorder $(p=, 000 ; \mathrm{OR}=26.0$; 95\%CI=10.5-64.0) and personality disorder ( $\mathrm{p}=.005$; OR=7.5; 95\%CI=1.8-30.8).

\section{Discussion}




\section{Main findings}

This study showed that IVF treatment is not associated with an increased risk of PND of a severity that requires psychiatric care. The initial findings instead indicated that those in the control group were at increased risk of PND but this difference disappeared when other covariates were controlled for in the multiple regression model . Meanwhile, a history of any psychiatric illness, or specifically a previous affective or personality disorder, were risk factors of PND. In total, 3.6\% of all the women in the study had suffered a psychiatric illness that required specialist psychiatric care during the five years prior to giving birth. The majority had suffered a depression (1.6\%) and/or an anxiety disorder (2.5\%). It was more common for the women in the control group than those in the IVF group to have suffered any category of psychiatric illness apart from anxiety disorders where there were no differences between the groups.

\section{Strengths and limitations}

The results of this study can only be generalized to severe cases of postnatal depression that require psychiatric care. The low multiple pregnancy rates found in this study also reduces the generalizability of the results since it is likely to be higher in other IVF settings and since the risk of PND can be increased in these patients ${ }^{41}$. A major limitation is that we were unable to control for some known risk factors of postnatal depression such as symptoms of depression and anxiety during pregnancy, life events, social support and marital satisfaction. As mentioned in the introduction, it is likely that the IVF women have fewer of these risk factors. They are, for example, more likely to have a supportive partner. It is possible that there are additional factors, of which we are not aware, that vary between the two groups. Also, we were unable to ascertain that there were no women among the controls that had undergone other forms of infertility treatment since only IVF treated women are included in 
the IVF register. Demographic data were not available for a large proportion of the participants due to missing information in the registers. For some diagnostic groups, for example schizophrenia and psychosis, there were small numbers and thus large confidence intervals.

Strengths of this study include a large study population and that no primiparous women who had given birth after IVF treatment during the specified time period were excluded. The registers used in this study are of good quality. We eliminated bias from age through matching, from parity through our inclusion criteria and bias from factors inherent to the current pregnancy or delivery, the previous pregnancy, previous psychiatric illness and demographics through regression analyses.

Interpretation

In accordance with most previous studies ${ }^{19-23}$, we did not find any evidence to indicate an increased risk of PND among the women treated with IVF. However, since the prevalence of PND that requires in- or outpatient psychiatric care is significantly lower than the general PND prevalence rates, the size of the present study might not be large enough to detect a difference between the groups.

Meanwhile, one might have expected that the stress caused by infertility and its treatment would cause increased cortisol levels, as showed by An et al. (2011) ${ }^{15}$, and thus that the risk of PND would be increased in these women. However, they also found that women with higher cortisol levels had a decreased chance of giving birth as a result of treatment ${ }^{15}$. Hence, the lack of differences in PND prevalence rates generally reported ${ }^{19-23}$ might be accounted for by a combination of two factors. First, the lower prevalence of known risk factors of PND, which reasonably all should have a negative effect on stress levels, in IVF women and second, the reduced likelihood of a positive treatment outcome in IVF women with high 
stress levels. Also, if PND is seen as an autoimmune disorder ${ }^{12}$ there is nothing known about these types of disorders that indicate that infertility or its treatment should increase the risk of PND, thus in concordance with our results.

In total, less than one percent of the women suffered a PND which corresponded to $0.4 \%$ of the women who had received IVF treatment and $0.8 \%$ of the controls. However, when comparing the present study to those conducted previously, it must be noted that the present study was not based on symptom rating scales but on diagnoses determined in psychiatric inor outpatient care and therefore the postnatal depression cases were most likely more severe than those in most previous studies.

Meanwhile, the prevalence found in this study is slightly higher than that reported by Räisänän et al (2013) who also studied in- and outpatient psychiatric care diagnoses and found a prevalence of $0.3 \%{ }^{3}$. Since a large part of our population consisted of women who had been accepted for IVF treatment which belong to a group known to be psychiatrically healthier than the general population this slightly higher prevalence is surprising. It is possible that this difference might be a result of a difference in the ICD-10 codes used for the postnatal depression diagnoses between our two studies. None of the women committed suicide during the first year after childbirth. While suicide is the cause of $20 \%$ of maternal deaths in the postnatal time interval, it is uncommon in absolute terms ${ }^{40}$. Hence, our findings were not unexpected.

Our results are in line with those of previous studies in showing that previous mental illness is a major risk factor for PND ${ }^{3,19-21}$. The reason for the higher prevalence of previous psychiatric illness among the controls might be that individuals with a history of severe 
psychiatric disease tend not to seek infertility treatment. This may in turn be caused by a fear that the strain of the treatment and/or having a child might be more than they can handle or that, in some cases, they are afraid to stop taking medication that might damage a fetus. Also, those who do seek infertility treatment might not be accepted for treatment if they suffer from a severe mental illness. Hence, adjusting for previous psychiatric disorders might not be sufficient to control for the potential effects of these confounders. However, we believe that our study population, including the distribution of previous psychiatric illnesses, reflects the patient material in most infertility clinics.

\section{Conclusion}

In conclusion, IVF treatment is not associated with an increased risk of PND. However, a history of psychiatric illness in general, or an affective or a personality disorder specifically, increases the risk of PND. Future studies on this topic should aim to control for all major risk factors of PND. 
Acknowledgements: None.

Contributors: JV participated in the conception and design of the article, analysis and interpretation of the data and drafted the paper. $\mathrm{MH}$ and $\mathrm{AJ}$ participated in the conception and design of the article, interpretation of the data and revised the paper. MB participated in analyses and interpretation of the data and revised the paper. GS had the original idea for the study and thus participated in the conception and design of the article and also in the interpretation of data and revised the paper.

Declaration of competing interests: All authors have completed the ICMJE uniform disclosure form at www.icmje.org/coi_disclosure.pdf and declare: no support from any organisation for the submitted work; no financial relationships with any organisations that might have an interest in the submitted work in the previous three years; no other relationships or activities that could appear to have influenced the submitted work.

Ethics: This study was approved by the Regional Ethical Review Board, Linköping, Sweden. No. 03-556, 03-557, 07-M66 08 - 08-M 233-8, 2010/403-31.

Funding: None. 


\section{References}

1. Gaynes BN, Gavin N, Meltzer-Brody S, Lohr KN, Swinson T, Gartlehner G et al. (2005) Perinatal depression: prevalence, screening accuracy, and screening outcomes. Evididence Report/Technology Assessment (Summary) 119, 1-8.

2. Josefsson A, Berg G, Nordin C, Sydsjö G (2001) Prevalence of depressive symptoms in late pregnancy and postpartum. Acta Obstetrica Gynecologica Scandinavica 80, 251-5.

3. Räisänen S, Lehto SM, Nielsen HS, Gissler M, Kramer MR, Heinonen S (2013) Fear of childbirth predicts postpartum depression: a population-based analysis of 511422 singleton births in Finland. BMJ Open 3, e004047.

4. Savitz DA, Stein CR, Ye F, Kellerman L, Silverman M (2011) The epidemiology of hospitalized postpartum depression in New York State, 1995-2004. Annals of Epidemiology 21, 399-406.

5. Meltzer-Brody S, Stuebe A (2014) The long-term psychiatric and medical prognosis of perinatal mental illness. Best Practice \& Research Clinical Obstetrics and Gynaecology 28, 49-60.

6. Waters CS, Hay DF, Simmonds JR, van Goozen S (2014) Antenatal depression and children’s developmental outcomes: potential mechanisms and treatment options. European Child and Adolescent Psychiatry 23,957-971.

7. Stein A, Pearson RM, Goodman SH, Rapa E, Rahman A, McCallum M et al. (2014) Effects of perinatal mental disorders on the fetus and child. Lancet 384, 1800-19.

8. Norhayati MN, Hazlina NH, Asrenee AR, Emilin W (2015) Magnitude and risk factors for postpartum symptoms: A literature review. Journal of Affective Disorders 175, 3452.

9. O’Hara MW, Wisner KL (2014) Perinatal mental illness: Definition, description 
and aetiology. Best Practice \& Research Clinical Obstetrics and Gynaecology 28, 3-12.

10. Robertson E, Grace S, Wallington T, Stewart DE (2004) Antenatal risk factors for postpartum depression: a synthesis of recent literature. General Hospital Psychiatry 26, 28995.

11. Glynn LM, Poggi Davis E, Sandman CA (2013) New insights into the role of perinatal HPA-axis dysregulation in postpartum depression. Neuropeptides 47, 363-370.

12. Gleicher N (2007) Postpartum depression, an autoimmune disease? Autoimmunity Reviews 6, 572-576.

13. Newton CR, Sherrard W, Glavac I (1999) The Fertility Problem Inventory: measuring perceived infertility-related stress. Fertility and Sterility 72,54-62.

14. Wichman CL, Ehlers SL, Wichman SE, Weaver AL, Coddington C (2011) Comparison of multiple psychological distress measures between men and women preparing for in vitro fertilization. Fertility and Sterility 95, 717-21.

15. An Y, Wang Z, Hongping J, Zhang Y, Wu K (2011) Pituitary-adrenal and sympathetic nervous system responses to psychiatric disorders in women undergoing in vitro fertilization treatment. Fertility and Sterility 96,404-8.

16. Hammarberg K, Rowe HJ, Fisher JR (2009) Early postpartum adjustment and admission to parenting services in Victoria, Australia after assisted conception. Human Reproduction 24, 2801-9.

17. Monti F, Agostini F, Fagandini P, La Sala GB, Blickstein I (2009) Depressive symptoms during late pregnancy and early parenthood following assisted reproductive technology. Fertiliy and Sterility 91, 851-857.

18. Lee S, Liu L, Kuo P, Lee M (2011) Postpartum Depression and Correlated Factors in Women Who Received In Vitro Fertilization Treatment. Journal of Midwifery \& Women’s health 54, 347-352. 
19. Hammarberg K, Fisher J, Wynter K (2008) Psychological and social aspects of pregnancy, childbirth and early parenting after assisted conception: a systematic review. Human Reproduction Update 14, 395-414.

20. Ross L, McQueen K, Vigod S, Dennis C (2011) Risk for postpartum depression associated with assisted reproductive technologies and multiple births: a systematic review. Human Reproduction Update 17, 96-106.

21. McMahon CA, Boivin J, Gibson FL, Fisher J, Hammarberg K, Wynter K et al. (2011) Older first-time mothers and early postpartum depression: a prospective cohort study of women conceiving spontaneously or with assisted reproductive technologies. Fertility and Sterility 96,1218-24.

22. Lynch CD, Prasad MR (2014) Association between infertility treatment and symptoms of postpartum depression. Fertility and Sterility 102,1416-21.

23. Listijono DR, Mooney S, Chapman M (2014) A comparative analysis of postpartum maternal mental health in women following spontaneous or ART conception. Journal of Psychosomatic Obstetrics abd Gynaecology 35, 51-54.

24. Klock SC, Greenfeld DA (2000) Psychological status of in vitro fertilization patients during pregnancy: a longitudinal study. Fertility and Sterility 73, 1159-1164.

25. Glazebrook C, Cox S, Oates M, Ndukwe G (2000) Psychological adjustment during pregnancy and the postpartum period in single and multiple in vitro fertilization births: a review and preliminary findings from an ongoing study. Reproductive Technologies 10, 112119.

26. Chatziandreou M, Madianos MG, Farsaliotis VC (2003) Psychological and personality factors and in vitro fertilization treatment in women. European Journal of Psychiatry 17, 223231.

27. Verhaak CM, Smeenk JM, Evers AW, Kremer JA, Kraaimaat FW, Braat DD (2007) 
Women's emotional adjustment to IVF: a systematic review of 25 years of research. Human Reproduction Update 13, 27-36.

28. Sydsjö G, Wadsby M, Sydsjö A, Ekholm Selling K (2008) Relationship and parenthood in IVF couples with twin and singleton pregnancies compared with spontaneous singleton primiparous couples_-a prospective 5-year follow-up study. Fertility and Sterility 89, 578585.

29. Kamphius EI, Bhattacharya S, van der Veen F, Mol BWJ, Templeton A (2014) Are we overusing IVF? British Medical Journal 348,g252.

30. National Board of Health and Welfare, Centre for Epidemiology. Pregnancies, Deliveries and Newborn Infants; The Swedish Medical Birth Register 1973-2007; Assisted Reproduction, treatment 1991-2006.

2009. http://www.socialstyrelsen.se/Lists/Artikelkatalog/Attachments/8316/2009-125-

5_20091255_rev3.pdf (accessed on 4 Feb 2013).

31. Harlow BL, Vitonis AF, Sparen P, Cnattingius S, Joffe H, Hultman CM (2007) Incidence of hospitalization for postpartum psychotic and bipolar episodes in women with and without prior prepregnancy or prenatal psychiatric hospitalizations. Archives of General Psychiatry 64, 42-48.

32. Dennis CL, Dowswell T. Psychosocial and psychological interventions for preventing postpartum depression (2013) Cochrane Database Systematic Reviews 2, CD001134. 33. Beck CT (1995) The effects of postpartum depression on maternal-infant interaction: A meta-analysis. Nursing Research 44, 298-304.

34. Josefsson A, Angelsiöö L, Berg G, Ekström CM, Gunnervik C, Nordin C et al. (2002) Obstetric, somatic, and demographic risk factors for postpartum depressive symptoms. Obstetrics \& Gynecology 99, 223-8. 
35. Källén B, Finnström O, Nygren K, Otterblad Olausson P (2005) In vitro fertilization (IVF) in Sweden: infant outcome after different IVF fertilization methods. Fertility and Sterility 8, 611-617.

36. Statistics Sweden (1974) Population and Housing Census 1970 (SOS); Part 12. Report on the planning and processing of the Population and Housing Census 1970. National Central Bureau of Statistics.

37. Statistics Sweden (2002) A new total population register system. More possibilities and better quality (Serial no. 2002:2). Statistics Sweden.

38. Statistics Sweden (2006) Evalvering av utbildningsregistret. Statistics Sweden.

39. Statistics Sweden (2009) Description of the population in Sweden 2008. Statistics Sweden.

40. Lindahl V, Pearson J, Colpe L (2005) Prevalence of suicidality during pregnancy and the postpartum. Archives of Women's Mental Health 8, 77-87.

41. Vilska S, Unkila-Kallio L, Punamäki RL, Poikkeus P, Repokari L, Sinkkonen J, et al. (2009) Mental health of mothers and fathers of twins conceived via assisted reproduction treatment: a 1-year prospective study. Human Reproduction 24, 367-377. 
Table 1. Demographics: Prevalence and chi-square tests

\begin{tabular}{|c|c|c|c|c|c|c|c|}
\hline & \multicolumn{2}{|c|}{ IVF } & \multicolumn{2}{|c|}{ Control } & \multicolumn{2}{|c|}{ Total } & \multirow[b]{2}{*}{$\mathrm{p}$} \\
\hline & $\mathrm{n}$ & $\%$ & $\mathrm{n}$ & $\%$ & $\mathrm{n}$ & $\%$ & \\
\hline & 3028 & 33.3 & 8553 & $66.6 \%$ & 12845 & 100 & \\
\hline \multicolumn{8}{|l|}{ Demographics } \\
\hline \multicolumn{8}{|l|}{ Marital status } \\
\hline Married/cohabiting & 2908 & 96.0 & 2593 & 87.6 & 5501 & 91.9 & \\
\hline \multirow[t]{2}{*}{ Single household } & 120 & 4.0 & 367 & 12.4 & 487 & 8.1 & \\
\hline & & & & & & & $.000^{*}$ \\
\hline \multicolumn{8}{|l|}{ Highest level of education } \\
\hline Secondary school & 236 & 7.8 & 192 & 6.5 & 428 & 7.2 & \\
\hline High school & 1475 & 49.0 & 1559 & 52.7 & 3034 & 50.8 & \\
\hline \multirow[t]{2}{*}{ University } & 1300 & 43.2 & 1206 & 40.8 & 2506 & 42.0 & \\
\hline & & & & & & & $.007^{*}$ \\
\hline \multicolumn{8}{|l|}{ Previous pregnancies } \\
\hline \multicolumn{8}{|l|}{$\begin{array}{l}\text { Stillborn/death during 1st } \\
\text { month }\end{array}$} \\
\hline One or more & 8 & 0.2 & 9 & 0.1 & 17 & 0.1 & \\
\hline \multirow[t]{2}{*}{ None } & 3524 & 99.8 & 8544 & 99.9 & 12068 & 99.9 & \\
\hline & & & & & & & .114 \\
\hline \multicolumn{8}{|l|}{ Miscarriages } \\
\hline One or more & 543 & 15.4 & 1089 & 12.7 & 1632 & 13.5 & \\
\hline \multirow[t]{2}{*}{ None } & 2989 & 84.6 & 7464 & 87.3 & 10453 & 86.5 & \\
\hline & & & & & & & $.000 *$ \\
\hline \multicolumn{8}{|l|}{ Current pregnancy } \\
\hline \multicolumn{8}{|l|}{ Gestational age } \\
\hline Extremely preterm $(<28)$ & 36 & 1.0 & 37 & 0.4 & 73 & 0.6 & \\
\hline Very preterm (28-32) & 88 & 2.5 & 60 & 0.7 & 148 & 1.2 & \\
\hline Preterm (32-36) & 416 & 11.8 & 498 & 5.8 & 914 & 7.6 & \\
\hline Term $(37-40)$ & 2212 & 62.9 & 5520 & 64.6 & 7732 & 64.1 & \\
\hline \multirow[t]{2}{*}{ Postterm $(>40)$} & 762 & 21.7 & 2436 & 28.5 & 3198 & 26.5 & \\
\hline & & & & & & & $.000 *$ \\
\hline \multicolumn{8}{|l|}{ Birth weight } \\
\hline ELBW $(<1000 \mathrm{~g})$ & 48 & 1.4 & 34 & 0.4 & 82 & 0.7 & \\
\hline VLBW (<1500g) & 89 & 2.5 & 51 & 0.6 & 140 & 1.2 & \\
\hline LBW (1500-2500g) & 368 & 10.5 & 324 & 3.8 & 692 & 5.7 & \\
\hline \multirow[t]{2}{*}{ Normal (>2500g) } & 3014 & 85.6 & 8126 & 95.2 & 11140 & 92.4 & \\
\hline & & & & & & & $.000 *$ \\
\hline \multicolumn{8}{|l|}{ Mode of delivery } \\
\hline Vaginal, spontaneous & 2532 & 72.8 & 5950 & 69.6 & 8522 & 70.5 & \\
\hline Vaginal, instrumental & 364 & 10.3 & 1219 & 14.3 & 1583 & 13.1 & \\
\hline Elective sectio & 192 & 5.4 & 419 & 4.9 & 611 & 5.1 & \\
\hline \multirow[t]{2}{*}{ Acute sectio } & 404 & 11.4 & 965 & 11.3 & 1369 & 11.3 & \\
\hline & & & & & & & $.000^{*}$ \\
\hline \multicolumn{8}{|l|}{ Plurality } \\
\hline Yes & 46 & 1.6 & 136 & 1.6 & 193 & 1.6 & \\
\hline No & 2825 & 98.4 & 8417 & 98.4 & 11837 & 98.4 & \\
\hline & & & & & & & .877 \\
\hline
\end{tabular}

Tests of significance using chi-square

*Significant at .05 level 


\begin{tabular}{|c|c|c|c|c|c|c|c|}
\hline & \multicolumn{2}{|c|}{ IVF } & \multicolumn{2}{|c|}{ Control } & \multicolumn{2}{|c|}{ Total } & \multirow[b]{2}{*}{$p$} \\
\hline & $\mathbf{n}$ & $\%$ & $\mathbf{n}$ & $\%$ & $\mathbf{n}$ & $\%$ & \\
\hline & 4292 & 100 & 8553 & 100 & 12385 & 100 & \\
\hline \multicolumn{8}{|l|}{ Diagnosis ( $\geq 1)$} \\
\hline \multirow[t]{2}{*}{$\begin{array}{l}\text { Any psychiatric (F20- } \\
43, \mathrm{F60})\end{array}$} & 87 & 2.5 & 355 & 4.2 & 442 & 3.7 & \\
\hline & & & & & & & $.000^{*}$ \\
\hline \multirow[t]{2}{*}{ Any affective (F30-39) } & 39 & 1.1 & 170 & 2.0 & 209 & 1.7 & \\
\hline & & & & & & & $.001 *$ \\
\hline \multirow[t]{2}{*}{$\begin{array}{l}\text { Manic or bipolar (F30- } \\
\text { 31) }\end{array}$} & 0 & 0.0 & 14 & 0.2 & 14 & 0.1 & \\
\hline & & & & & & & $.015^{*}$ \\
\hline \multirow[t]{2}{*}{ Depression (F32-39) } & 39 & 1.1 & 159 & 1.9 & 198 & 1.6 & \\
\hline & & & & & & & $.003^{*}$ \\
\hline \multirow[t]{2}{*}{$\begin{array}{l}\text { Schizophrenic or } \\
\text { psychosis (F20-29) }\end{array}$} & 1 & 0.0 & 6 & 0.1 & 7 & 0.1 & \\
\hline & & & & & & & .681 \\
\hline \multirow[t]{2}{*}{$\begin{array}{l}\text { Schizophrenic (F20- } \\
\text { 22, F24-25) }\end{array}$} & 0 & 0.0 & 3 & 0.0 & 3 & 0.0 & \\
\hline & & & & & & & .556 \\
\hline \multirow[t]{2}{*}{$\begin{array}{l}\text { Other psychosis (F23, } \\
\text { F28, F29) }\end{array}$} & 1 & 0.0 & 5 & 0.1 & 6 & 0.0 & \\
\hline & & & & & & & .678 \\
\hline \multirow[t]{2}{*}{$\begin{array}{l}\text { Anxiety disorder (F40- } \\
\text { 43) }\end{array}$} & 62 & 1.8 & 240 & 2.8 & 302 & 2.5 & \\
\hline & & & & & & & $.001 *$ \\
\hline \multirow[t]{2}{*}{ Fobic disorder (F40) } & 4 & 0.1 & 37 & 0.4 & 41 & 0.3 & \\
\hline & & & & & & & $.008 *$ \\
\hline \multirow[t]{2}{*}{$\begin{array}{l}\text { Other anxiety } \\
\text { disorder (F41) }\end{array}$} & 34 & 1.0 & 148 & 1.7 & 182 & 1.5 & \\
\hline & & & & & & & $.002 *$ \\
\hline \multirow[t]{2}{*}{$\begin{array}{l}\text { Obsessive } \\
\text { compulsive disorder } \\
\text { (F42) }\end{array}$} & 1 & 0.0 & 9 & 0.1 & 10 & 0.1 & \\
\hline & & & & & & & .299 \\
\hline \multirow[t]{2}{*}{$\begin{array}{l}\text { Reactions to severe } \\
\text { stress (F43) }\end{array}$} & 31 & 0.9 & 88 & 1.0 & 119 & 1.0 & \\
\hline & & & & & & & .477 \\
\hline \multirow[t]{2}{*}{$\begin{array}{l}\text { Personality disorder } \\
\text { diagnosis (F60) }\end{array}$} & 7 & 0.2 & 44 & 0.5 & 51 & 0.4 & \\
\hline & & & & & & & $.016^{*}$ \\
\hline
\end{tabular}




\begin{tabular}{|c|c|c|c|}
\hline & \multicolumn{3}{|c|}{ Postpartum depression (F32-39) } \\
\hline & OR & $\mathbf{p}$ & C.I. \\
\hline \multicolumn{4}{|l|}{ Covariates } \\
\hline \multicolumn{4}{|l|}{ Group 1: Demographics } \\
\hline \multicolumn{4}{|l|}{ Age } \\
\hline $20-24$ & \multicolumn{3}{|c|}{ Reference level } \\
\hline $25-30$ & 1.844 & .401 & $.441-7.706$ \\
\hline $30-34$ & 2.125 & .297 & $.515-8.778$ \\
\hline \multicolumn{4}{|l|}{ Marital status } \\
\hline Married/cohabiting & \multicolumn{3}{|c|}{.Reference level } \\
\hline Single & 3.310 & $.006^{*}$ & $1.411-7.766$ \\
\hline \multicolumn{4}{|l|}{ Education } \\
\hline Secondary School & \multicolumn{3}{|c|}{ Reference level } \\
\hline High School & 1.261 & .760 & $.284-5.591$ \\
\hline University & 1.750 & .463 & $.393-7.794$ \\
\hline \multicolumn{4}{|c|}{ Group 2: Previous pregnancies } \\
\hline \multicolumn{4}{|c|}{ Miscarriages } \\
\hline No & \multicolumn{3}{|c|}{ Reference level } \\
\hline Yes & 1.582 & .102 & $.913-2.741$ \\
\hline \multicolumn{4}{|c|}{ Group 3: Current pregnancy } \\
\hline \multirow{2}{*}{\multicolumn{4}{|c|}{$\begin{array}{l}\text { Gestational age (week) } \\
\text { Preterm }(<37)\end{array}$}} \\
\hline & & & \\
\hline Term $(\geq 37)$ & .482 & .080 & $.213-1.092$ \\
\hline \multicolumn{4}{|l|}{ Birth weight } \\
\hline$>2500 \mathrm{~g}$ & \multicolumn{3}{|c|}{ Reference level } \\
\hline$\leq 2500 \mathrm{~g}$ & 1.847 & .282 & $.604-5.647$ \\
\hline \multicolumn{4}{|l|}{ Group } \\
\hline IVF & \multicolumn{3}{|c|}{ Reference level } \\
\hline Control & 1.834 & $.037^{*}$ & $1.039-3.237$ \\
\hline \multicolumn{4}{|l|}{ Group 4: Childbirth } \\
\hline \multicolumn{4}{|l|}{ Mode of childbirth } \\
\hline Vaginal, spontaneous & \multicolumn{3}{|c|}{ Reference level } \\
\hline Vaginal, instrumental & 1.073 & .892 & $.387-2.978$ \\
\hline Elective caesarian section & 1.199 & .601 & $.608-2.364$ \\
\hline Acute caesarian & 1.558 & .132 & $.875-2.775$ \\
\hline $\begin{array}{l}\text { Group 5: Psychiatric d } \\
\text { previous to birth of ch }\end{array}$ & & & \\
\hline Psychiatric disorder (F20 & & & \\
\hline No & Refere & & \\
\hline Yes & 8.355 & $.000 *$ & $3.100-22.520$ \\
\hline Affective disorder (F30-3 & & & \\
\hline No & Refere & & \\
\hline Yes & 5.416 & $.000^{*}$ & $2.347-12.497$ \\
\hline $\begin{array}{l}\text { Schizophrenia or psycho } \\
\text { 29, F53) }\end{array}$ & & & \\
\hline No & Refere & & \\
\hline Yes & 2.155 & .541 & $.184-25.297$ \\
\hline Anxiety disorder (F40-42 & & & \\
\hline No & Refere & & \\
\hline Yes & 1.214 & .594 & $.595-2.478$ \\
\hline Personality disorder (F60 & & & \\
\hline No & Refere & & \\
\hline Yes & 2.971 & $.008^{*}$ & $1.330-6.636$ \\
\hline Constant & & & \\
\hline
\end{tabular}

